\title{
Digital News Media Coverage on Sexual and Gender-Based Violence in Kenya: Scoping the Impact of the COVID-19 Pan- demic
}

Clara Broekaert, Ceri-Lune Renneboog, Ferdinand Okwaro, Abdu Mohiddin, Marleen Temmerman.

\begin{abstract}
Background: Sexual and gender-based violence (SGBV) in Kenya is frequently covered in digital news media. As a powerful influencer of public opinion, news media coverage can have a significant societal impact. This scoping review identifies the extent, nature, and themes of all available digital news media coverage on SGBV in Kenya from June 2019 to July 2020. It analyzes changes in coverage since the start of the COVID-19 pandemic.

Method: The methodological framework for scoping reviews developed by Arksey and O'Malley (2005) guided the scoping review. The selected articles were analyzed using NVivo.

Results: Analysis of the 340 included articles indicates clear trends in news media coverage on SGBV in Kenya. Before the COVID-19 pandemic, trends include high numbers of news reports, feature articles, and opinion pieces on SGBV, female genital mutilation (FGM) as the most covered form of SGBV, and opinion pieces in line with the Kenya Vision 2030 agenda. Since the implementation of the COVID-19 mitigation measures in Kenya, trends include an increase in news media coverage on SGBV, extensive reporting on the causes of the rise in SGBV cases in Kenya, and increased media attention for domestic and sexual violence.

Conclusions: Analysis of the news media coverage demonstrates the health advocacy/agenda-setting role of the media. The increased reporting on SGBV since the implementation of the COVID-19 mitigation measures could facilitate broad-based awareness. Key Words: SGBV, Kenya, Media, COVID-19 Pandemic, Scoping Review.
\end{abstract}

\section{Introduction}

In April of 2020, The United Nations Population Fund (UNFPA) projected that there would be 31 million additional cases of gender-based violence if the lockdown continued for at least six months and a further 15 million cases for every three months of lockdown. Cases of FGM and child marriage are expected to soar by 2 million and 13 million between 2020 and 2030 respectively due to the COVID-19 pandemic and the mitigation measures (UNFPA, 2020).
As the media serves as an influential shaper of public opinion (McCombs, 2011), this paper investigates how digital news media has changed its coverage of SGBV in Kenya since the onset of the COVID-19 pandemic. Underpinned by the methodological framework for scoping reviews proposed by Arksey and O'Malley (2005), this study identifies the extent, nature, and themes of media coverage on SGBV in Kenya before and after the onset of the 
COVID-19 pandemic. This study's overarching objective is to examine changes in the digital news media coverage of SGBV and other associated harmful practices related to the COVID-19 pandemic.

\section{Background}

\section{COVID-19}

In May 2020, the World Health Organization (WHO) estimated that Africa could report up to 190,000 deaths and 44 million infections due to COVID-19 in the first year of the pandemic if mitigation measures were not rigorously implemented. After the first case of COVID-19 was reported in Kenya on March $15^{\text {th }}, 2020$, a series of mitigation measures were implemented. These included a travel ban for foreigners, closure of educational institutions, the creation of a toll-free telephone line to report cases, the directive for all nonessential private and public institutions to work from home, the prohibition of all social and religious gatherings, and a mandatory stay at a quarantine center for returning nationals, residents, and those who had contact with individuals infected with COVID-19. Later in March, all international flights were suspended. A mandatory stay at quarantine centers for those who violated the mitigation measures was imposed, and a nationwide dusk-todawn curfew was set. In early April, the cessation of movement into and out of the Nairobi Metropolitan Area, Mombasa County, Kilifi County, Mandera County, and Kwale County took effect to curb the spread of COVID-19 and has been partially lifted as of July (Ministry of Health, 2020). On April $4^{\text {th }}$, the government mandated the use of masks in all public spaces. These formal mitigation measures were promoted through information campaigns concerned with recognizing symptoms of the coronavirus disease, applying appropriate hygiene measures, and dealing with the psychological repercussions of the mitigation measures. However, the COVID-19 mitigation measures implemented in Kenya have been subject to wide-ranging debates. Critics point to the poor living conditions in the quarantine centers that have made applying the appropriate physical distancing and hygiene measures near to impossible (Mutahi, 2020). The Kenyan government and police have also come under scrutiny for the use of excessive violence to enforce the curfew (Nyabola, 2020).

\section{Sexual and Gender-Based Violence}

This study adopted the definition of SGBV proposed by the United Nations High Commissioner for Refugees (UNHCR) as "any act that is perpetrated against a person's will and is based on gender norms and unequal power relationships. It encompasses threats of violence and coercion. It can be physical, emotional, psychological, or sexual in nature and can take the form of a denial of resources or access to services. It inflicts harm on women, girls, men, and boys" (2020).

In 2014, the National Crime Research Center (NCRC) of Kenya published a study on the prevalence, causes, and effects of SGBV at the community level. The study found a lifetime GBV prevalence rate of $38 \%$ for women and $20.9 \%$ for men, and a lifetime sexual violence rate of $15.2 \%$ for women and $7.5 \%$ for men in Kenya. The Kenya Demographic and Health Survey of 2014 established that $47 \%$ of women aged 15 to 49 have experienced physical or sexual violence. Furthermore, the United Nations Children's Fund (UNICEF) found that $21 \%$ of Kenyan girls and women aged 15 to 49 have been subjected to female genital mutilation despite 
the passing of the Prohibition of Female Genital Mutilation Act in 2011. Similarly, in $2017,23 \%$ of Kenyan girls were married before 18 - the Marriage Act of 2014 set the minimum legal age of marriage at 18 without exceptions (Girls Not Brides, 2018). Some of the factors underlying SGBV in Kenya include "the low status of women in society, patriarchal values and power structures focused on male dominance, discriminatory institutions and implementation of laws, the absence of a legal framework on intimate partner violence (IPV), and a criminal justice system that is largely inaccessible" (Mc Evoy, 2012; NCRC, 2014).

\section{Kenya's Media Landscape}

Kenya's media landscape underwent digital migration in 2015. Digital migration expands radio frequencies on the radio spectrum, allowing media companies to benefit from lower broadcasting costs while providing better viewing quality (Spectrum, 2017). From 2011 to 2015, this digital migration expanded media coverage in Kenya by increasing the population covered by television broadcasting from 55\% to $66 \%$, the number of television broadcasters from 14 to 65 , and the number of broadcasters reaching multiple cities from 5 to 22. Although radio and television remain the most commonly used media platforms by Kenyans, there is a steady increase in the use of online news sources, read by $30 \%$ of Kenyans (Reelforge \& Tifa 2019). In contrast, only $10 \%$ of Kenyans read a newspaper in the week before the Reelforge and Tifa survey in that same year - down from $27 \%$ in 2014 . An examination of the websites most visited in Kenya demonstrates that news sources including Standard Media, Nation, Tuko, Kenyans, Citizen TV,
Google, and Yahoo were popular (Reelforge \& Tifa Research, 2019). As smartphone use and access to the internet continues to expand in Kenya, media outlets will further digitize, and digital news will likely increase their readership.

News media has been identified as an influential agenda-setting factor and public opinion shaper (McCombs, 2011). As our perception of events is heavily influenced by what we read in the media, "the priorities of the media strongly influence the priorities of the public" (McCombs, 2011). The media prioritizes and frames specific issues, thus shaping public opinion and priority (Seale, 2002). The UN Women Europe and Central Asia Media Coverage of Gender-Based Violence handbook, published in 2017, addresses media reportage protocols and highlights the importance of reporting SGBV "in a responsible way," recognizing the impact media reporting can have on the public perceptions of SGBV (UN Women, 2017).

\section{Methods}

Due to the rapidly-paced publication of news articles on SGBV in Kenya since the start of the COVID-19 outbreak, the research team opted for the scoping review method. As detailed by Arksey and O'Malley, this method allows for a comprehensive and descriptive-analytical overview (2005). Their five-stage framework methodology guides our inquiry into the news coverage on SGBV in Kenya.

\section{Identifying the initial research ques- tions}

The research question was defined as follows: "How did the media report on the issue of SGBV in Kenya before the COVID pandemic? How did media reporting on the 
issue of SGBV change during the COVID pandemic?" The following subsidiary questions were formulated:

$>$ What is the extent of media coverage before and since the pandemic?

$>$ What is the nature of the media coverage before and since the pandemic?

$>$ What are the recurring themes of the media coverage before and since the pandemic?

\section{Identifying relevant articles}

A comprehensive search was conducted to identify all relevant articles from digital news media sources reporting on SGBV in Kenya preceding and during the COVID-19 pandemic. The databases PressReader ${ }^{\circledR}$ and AllAfrica ${ }^{\circledR}$ were used. In addition, Yahoo!News ${ }^{\circledR}$ and Google News ${ }^{\circledR}$ were searched to increase the chances of capturing all relevant articles. In the identification process, numerous combinations of keywords were used to capture the articles on SGBV, as detailed in Table 1.

\begin{tabular}{|l|}
\hline Table 1 \\
\hline Keywords \\
\hline "gender-based violence" OR "sexual violence" OR \\
"domestic violence" OR "child marriage" OR "female \\
genital mutilation" AND "Kenya"
\end{tabular}

The inclusion and exclusion criteria used the following definitions and constraints:

Digital News Media: All news sources accessible via digital electronics devices regardless of orientation and biases. The news output of international organizations (e.g., WHO) and NGOs (e.g., Human Rights Watch) were also considered as news media.
Language Constraints. Only those articles written in English were identified.

Time Period. All relevant articles were identified from the 1st of June 2019 to the 18th of July 2020. This period allowed us to compare pre-pandemic and pandemic media coverage.

$S G B V$ in Kenya. All news articles that discuss fully or partially SGBV, as per the UNHCR definition, in Kenya were considered. This includes articles that report on patterns as well as on individual cases of SGBV.

\begin{tabular}{|l|l|l|}
\hline \multicolumn{2}{|l|}{ Table 2} \\
\hline Inclusion and Exclusion Criteria \\
\hline Criterion & Inclusion & Exclusion \\
\hline Source & Digital media & $\begin{array}{l}\text { Print media, academic } \\
\text { literature, and grey literature }\end{array}$ \\
\hline Language & English & Any other language \\
\hline Time period & June 2019 to July 2020 & $\begin{array}{l}\text { Articles published outside set } \\
\text { time frame }\end{array}$ \\
\hline Article Focus & $\begin{array}{l}\text { SGBV in Kenya as per set } \\
\text { constraints and definition of } \\
\text { concept }\end{array}$ & $\begin{array}{l}\text { Articles that do not cover } \\
\text { Kenya specifically, articles that } \\
\text { do not fit set constraints and } \\
\text { definition of SGBV }\end{array}$ \\
\hline
\end{tabular}

\section{Results}

\section{Article selection}

Search queries of the keywords identified an initial 3966 articles. The databases identified substantially more articles than Yahoo!News ${ }^{\circledR}$ and Google News ${ }^{\circledR}$. The algorithms of the latter websites limit results to the most popular and relevant articles. Furthermore, Google News ${ }^{\circledR}$ provides 100 results per search query as a standard, which limited article identification. Through a review of the titles and sources of the articles, 1217 duplicate articles were excluded. The second level of screening based on publication date and the content of the article titles (demonstrating clear relevance to the study) excluded 2084 articles. The 665 articles that remained were fully assessed for eligibility as per the set inclusion and exclusion criteria and were further 
reduced to 340 articles, included in the scoping review. Figure 1 illustrates the process of the article selection. The most frequent reason for exclusion was when an article did not cover SGBV in Kenya specifically and instead reported SGBV trends regionally or globally. Some articles appeared in searches on PressReader ${ }^{\circledR}$ and were not digitally accessible. This was the case when the original article was part of the paper edition of the news source and not its digital edition and was consequently excluded from the scoping review. Furthermore, some news sources published the same article under different titles in their digital and paper editions. In this case, the paper duplicate was excluded.

\section{Charting data}

At this stage, the data of all included articles were charted. Figure 2 details the frequency of article publication. Figure 3 details the news sources of the included articles. Figure 4 depicts the news sources of the articles over time. Developed with NVivo, a computer-assisted qualitative data analysis software, Figure 5 depicts the types of articles, and Figure 7 charts the recurring themes of media coverage.

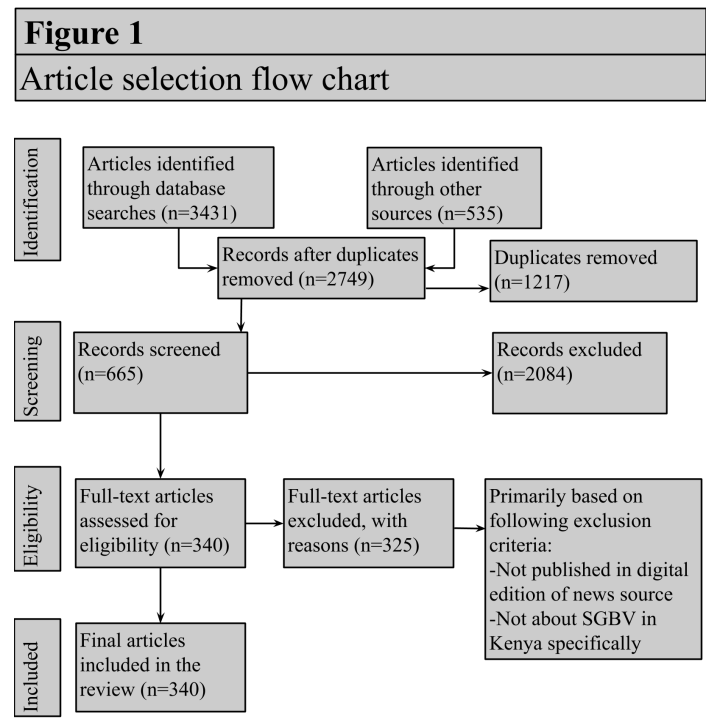

\section{Findings}

I. What is the extent of media coverage before and since the pandemic?

To formulate the influence of the COVID19 pandemic on SGBV media coverage, the frequency of article publication and the diversity of news sources were examined. The analysis of the frequency of publication of SGBV-related articles demonstrates a clear and logical connection between significant events, reports, and incidents concerned with SGBV and increased media coverage. The Nairobi Summit on ICPD25, concerned with advancing the sexual and reproductive health and rights agenda, prompted a spike in articles in November 2019 when it was held.

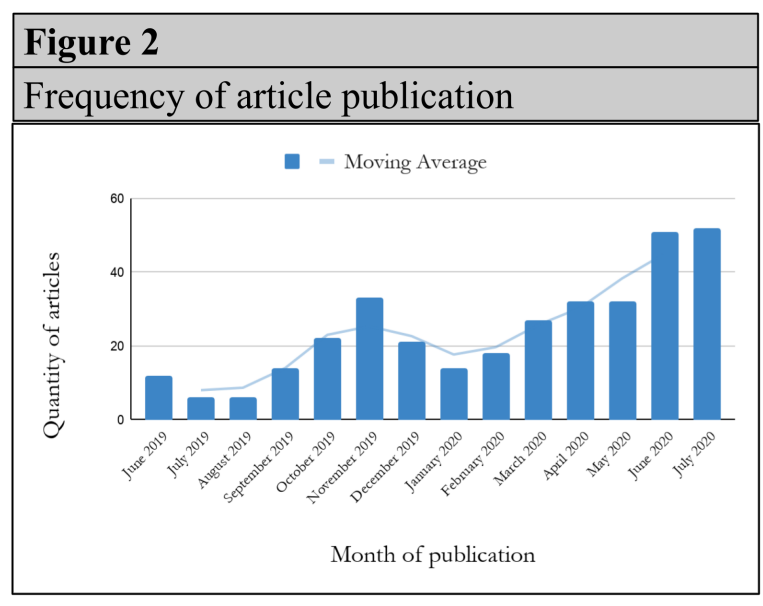

The second rise in news articles on SGBV followed the implementation of COVID-19 mitigation measures in Kenya on the 15 th of March 2020. 160 articles were published over the 9.5 months from the 1st of June 2019 to the 15th of March 2020, and 180 articles were published over the four months from the 15th of March 2020 to the 18th of July 2020. The moving average trendline (period of three) further demon- 
strates the upward trend of article publication since the start of the COVID-19 pandemic in Kenya.

Although SGBV in Kenya is by international press and organizations, two Kenyan news outlets, The Star and Daily Nation, prominently report on it. They are followed by non-governmental organizations Human Rights Watch and ReliefWeb, as well as international news venues such as The Guardian, BBC, etc.

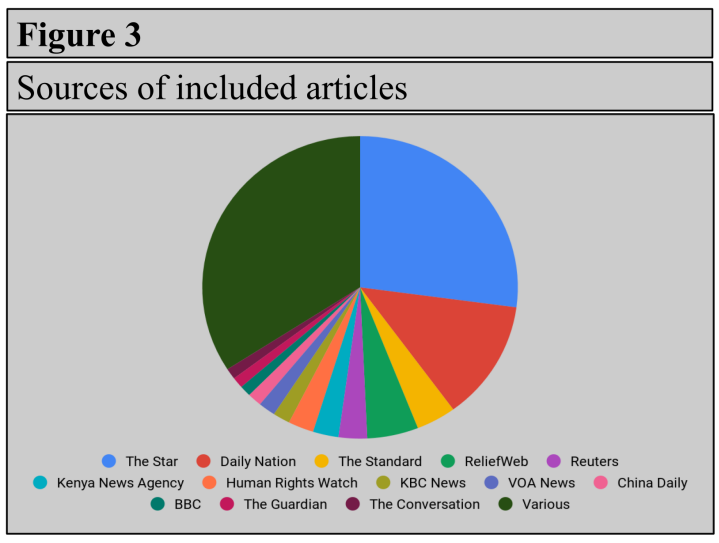

As demonstrated by figure 4 , since the start of the COVID-19 pandemic, there is an increase in SGBV coverage by news sources that do not typically report on the issue.

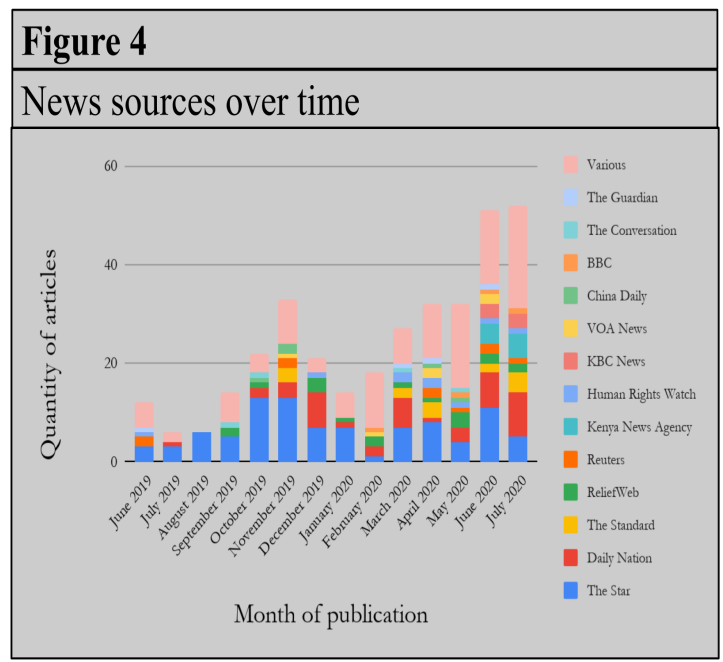

II. What is the nature of the media coverage before and since the pandemic?

The nature of the media coverage was examined by inquiring into the type of articles published on SGBV. The research team used March 15th as the dividing line between articles published "before" and "since" the implementation of the COVID19 mitigation measures. NVivo software was used to code the articles as either news reports, feature articles, opinion pieces, reviews, or obituaries to capture the variety of articles that discuss, fully or partially, SGBV in Kenya.

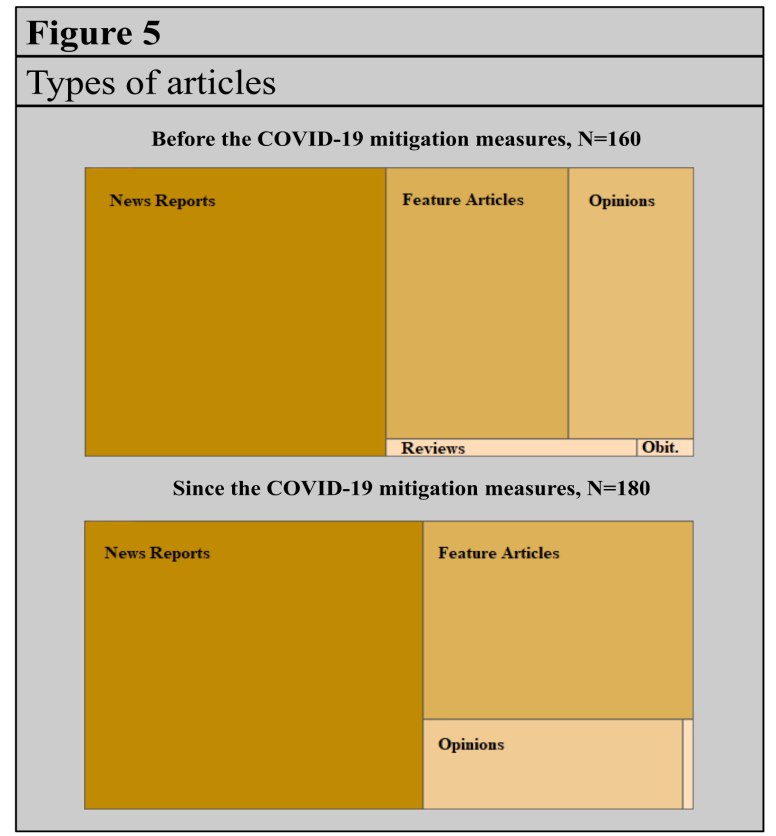

Inquiry into the nature of SGBV included a wide variety of article types that cover SGBV in Kenya. News reports (predominantly in Kenyan news sources), feature articles (in Kenyan, international, and NGO news sources) as well as opinion pieces (primarily in Kenyan news sources) were the most shared article types covering the subject. Notably, feature articles offered an in-depth analysis of the rise of sexual and 
gender-based violence such as domestic violence, female genital mutilation, and child marriage due to the COVID-19 pandemic. They also offered insight into different individual, governmental, non-governmental, and corporate prevention, recovery, and justice efforts. Nearly all opinion pieces presented progressive stances on SGBV in line with the sustainable development goals and Kenya Vision 2030. One of the guiding programs of Kenya Vision 2030 for SGBV seeks to strengthen women's participation in reconciliation and peace committees and prioritizes education on SGBV. Opinion articles concerned the promotion of these principles and simultaneously shed light on recent cases and trends of SGBV in Kenya.

\section{What are the recurring themes of the} media coverage before and since the pandemic?

NVivo software was used to scope the themes and subthemes of news media coverage. A hierarchy of nodes was created to find the overarching themes in the included articles (FGM, child marriage, domestic violence, LGTBQ+ violence, and general SGBV) as well as the subthemes (trends, rates, cases, increases, consequences, causes, barriers to recovery and justice services, legal protections, etc.). One article covering multiple themes and subthemes of SGBV was coded to multiple nodes to accurately reflect this. The date of the implementation of the mitigation measures in Kenya, the 15th of March, was again utilized as an artificial redline to divide articles published "before" and "since" the COVID-19 pandemic mitigation measures.

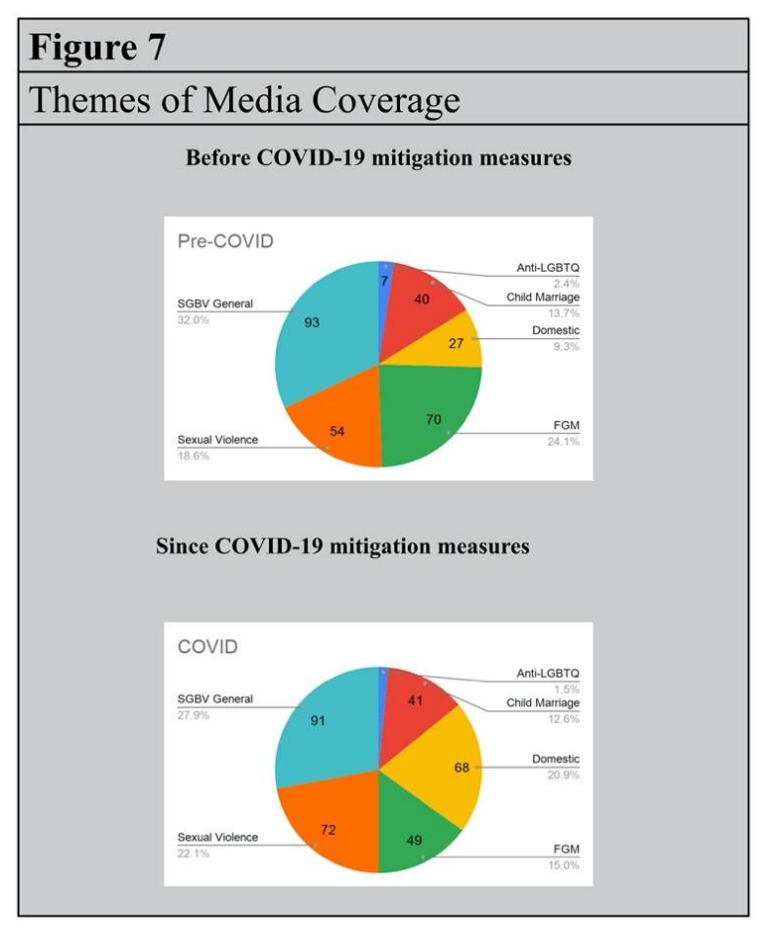

\section{Female Genital Mutilation}

Before the COVID-19 mitigation measures, in the 70 articles that discussed FGM, the most recurring subtheme was prevention, recovery, and justice efforts by individual, governmental, and non-governmental actors (51 articles). Awareness-raising and educational opportunities (42 articles), the pledge by President Uhuru Kenyatta to end FGM in Kenya by 2022 at the Nairobi Summit on ICPD25 (23 articles), the promotion of alternative rites of passage ( 9 articles), and least frequently, clitoral reconstruction (2 articles), were all covered within this subtheme. The second most recurring subtheme in media coverage was the causes of FGM (37 articles) identified as retrogressive traditional beliefs (34 articles), FGM as the prerequisite to marriage (16 articles), and FGM as the promotion of chastity ( 8 articles).

The barriers to the eradication of FGM (27) were identified as cross-border FGM 
to and from Kenya (11), the growing trend of underground FGM (8), the lack of education around the negative consequences of FGM (8), the absence of a harmonious eradication strategy among stakeholders (4), and the medicalization of FGM (7). Legal provisions that protect from FGM, in particular the Prohibition of Female Genital Mutilation Act of 2011, were also frequently mentioned in media coverage (31 out of the 70 articles that covered FGM pre-COVID-19) - usually in context that despite the criminalization of FGM it remains widely practiced. The negative consequences of FGM were covered in 21 articles. The health repercussions were identified as sexual and reproductive complications, chronic conditions, psychological trauma, physical injury, and death. The cut, indicated in the included articles as a precondition to marriage, was also identified as a cause of high teenage pregnancy rates.

The next most recurring subtheme in media coverage was trends of FGM in Kenya (17). The media covered a higher FGM prevalence rate among certain ethnic communities and geographies such as the Maasai, Somalis, and Pokot and the Northeastern counties respectively (13). Another reported trend was the progress of Kenya in the eradication of FGM in the last decade (6). Articles also covered cases of FGM, typically not anonymized in feature articles and anonymized in news reports (15). Another recurring subtheme was the national prevalence rate of FGM, established at $21 \%$ for women between the age of 15 and 49 (17). Other less covered subthemes included the different forms of FGM practiced in Kenya (12) and the legal challenge to the FGM Prohibition Act filed by Dr.
Tatu Kamau on the grounds that it is an infringement to the right to exercise one's cultural beliefs (4).

The aforementioned subthemes of FGM were also covered by the media after the implementation of the COVID-19 mitigation measures. In the 49 articles on FGM published since the COVID-19 pandemic, two other recurring subthemes emerged: the causes of the increase of FGM cases since March 2020 (28) and the further consequences of the mitigation measures (10). The reported increase in FGM cases was attributed to the imposed lockdown (24), including school closures, that created the ideal environment for families to arrange for their girls to undergo FGM. The other reported cause was the economic implications of the COVID-19 mitigation measures, prompting families to prepare their girls for (child) marriage to receive a dowry and cushion economic hardship (14). Another reported FGM-related consequence of the lockdown includes a difficult environment for prevention, recovery, and justice initiatives to operate (10) with shelters and rescue centers closed, cross-border dialogue to intercept "FGM tourism" halted, community outreach programs suspended, and the number of social workers and law enforcement officials within communities strongly diminished.

\section{$S G B V$}

Before the implementation of the COVID19 mitigation measures, of the 93 articles that covered SGBV in Kenya generally, the most recurring subtheme was prevention, recovery, and justice efforts (58). Efforts included Kenya's pledge to eradicate GBV practices by 2030 (5), the Nairobi Summit (22), men's participation in the eradication 
of SGBV (5), and the individual, governmental, and nongovernmental prevention, recovery, and justice efforts focusing on education, care services, and accountability, (44 articles). Furthermore, trends of SGBV received substantial media attention (27). These trends included delayed justice for survivors of SGBV (9) and human trafficking of women to and from Kenya, making them prone to sexual and domestic abuse (4). The media also identified several groups as particularly vulnerable to SGBV (6) such as (poor) women and girls, tea plantation workers, people living with disabilities, and people not enrolled in the civil register. Other trends included the increase of SGBV during school holidays (4), men as survivors of SGBV (1), cyberbullying as an emerging form of SGBV in Kenya (2), and the progress towards eliminating SGBV (2). Rates of SGBV in Kenya were also covered (27). They reported the estimated national prevalence rate of SGBV against women and girls of $47 \%$, county prevalence rates, and occasional increases in cases locally or nationally.

Individual cases of SGBV in Kenya also received significant media attention and included cases of femicide, physical harassment, and verbal abuse (13). Media coverage on legal provisions that protect from SGBV (15) encompassed references to the Constitution of Kenya (2010), the Policy on Gender and Development (2019), the National Policy for the Eradication of FGM (2019), the Sexual Offences Act (2006), the Counter-Trafficking Act (2011), the Children's Act (2001), the Prevention against violence Act (2015), the Prohibition of Female Genital Mutilation Act (2011), and international conventions Kenya is party to. These are usually mentioned in the context of Kenya's active agenda in eradicating SGBV or the high rates of SGBV despite extensive legal provisions. The causes of SGBV were reported in the media (14) as retrogressive traditional beliefs (7), poverty (4), lawlessness and conflict (3), and a mental health crisis (1). The reported health consequences of SGBV underlined sexually transmitted infections (especially HIV), sexual and reproductive health (SRH) complications, psychological trauma, physical injury, and death. Media coverage on the economic repercussions of SGBV underlined its dramatic effect on an individual's wellbeing and the Kenyan economy. The various forms of SGBV were also indicated as a critical cause of the low school attendance rates by young girls.

After the implementation of the COVID-19 mitigation measures, in the 91 articles reporting on SGBV, prevention, recovery, and justice efforts remained the most frequently covered subtheme (56). The increase in cases of SGBV, both locally and nationally, was also frequently covered (48): SGBV cases had tripled in the first three months of the dusk-to-dawn curfew, and the national GBV hotline, in June 2020, reported a $650 \%$ increase in calls since the implementation of the COVID-19 mitigation measures. As instances of SGBV increased due to mitigation measures and the national lockdown, media coverage began discussing the heightened number of calls to GBV hotlines as an indicator for this increased SGBV prevalence. Nairobi, Kisumu, Mombasa, Kwale, Kilifi, Isiolo, and Homa Bay, also reported local increases in SGBV cases (7). The next most recurring subtheme in media coverage was trends of SGBV since the COVID-19 pandemic (29). Trends included relatives and guardians as 
main perpetrators of SGBV (14), vulnerable groups being disproportionately victimized (women, girls, and children - especially in informal settlements and pastoral and remote communities) (13), the mitigation measures as barriers to services for survivors of SGBV (2), and the low awareness among Kenyans of SGBV support services (1). Media coverage also identified the causes of the increase of SGBV cases (14). These included economic repercussions of the COVID-19 mitigation measures, which have increased stress, uncertainty, and fear for many (8) and the lockdown itself that has closed schools and limited mobility (7). Other subthemes largely corresponded to pre-pandemic media coverage.

\section{Sexual Violence}

Media coverage on sexual violence in Kenya before the implementation of the COVID-19 mitigation measures (54) was mostly concerned with trends of sexual violence (25). This included guardians, relatives, acquaintances, and security force agents as common perpetrators (13) and sexual violence in post-election settings (11). Other reported trends included the underreporting of sexual violence (6), men as survivors of sexual violence (3), transactional sex in coastal counties (1), and sodomy (1). Individual cases of sexual violence (22) and prevention, recovery, and justice efforts of individuals, governmental, and nongovernmental organizations (22) were the next most recurring subthemes. Reported consequences of sexual violence (15) included teenage pregnancies (5), stigma and social exclusion (9), and health issues such as physical injuries, sexually transmitted diseases, and psychological trauma (4). The media coverage on the prevalence of sexual violence in Kenya (13) depicted several different sources of estimates, including: The Gender-Based Violence Recovery Centre in Mombasa, which estimated that 1 in 3 girls have experienced sexual violence before the age of 18 , and the Demographic Health Survey of 2014, which established that $14 \%$ of women aged 15 to 49 have experienced sexual violence. The next subtheme that received substantial media attention was barriers to reporting, recovery, and justice efforts (11). These encompassed lack of awareness about available services (5), victim-blaming and stigma (4), lack of child-friendly spaces in court and police offices (2), post-election unrest (1), and lack of shelter for survivors (1). Media coverage on the legal provisions that protect from sexual violence referred to the Constitution of Kenya (2010) that stipulates the right to be free from violence and the Sexual Offences Act (2006), that stipulates protection from a range of sexual abuses (10). Causes of sexual violence were not frequently reported (2).

After the implementation of the COVID-19 mitigation measures, of the 72 articles concerned with sexual violence, the most covered subtheme was the increase in sexual violence since the implementation of the mitigation measures (38) with reporting that sexual violence accounted for up to $35.8 \%$ of reported crimes in the first three weeks of the dusk-to-dawn curfew. The next most-recurring theme were the causes of this increase (32) including the lockdown and consequent school closures bringing people, especially women and children, in situations where they are vulnerable to sexual violence (28). The media reported that the economic repercussions of the mitigation measures also contributed to the increase of sexual violence with an increasing number of girls prone to sexual assault 
while trying to secure a livelihood for themselves, parents moving to secure an income and leaving their children in high-risk situations, and an upwards trend in transactional sex (9). Other subthemes were similar to those covered before the COVID-19 pandemic.

\section{Anti-LGBTQ Violence}

The media coverage on anti-LGBTQ violence in Kenya that was picked up by our search queries (7) most frequently broadcasted the criminalization of same-sex acts (5). Trends (4) and cases (3) of antiLGBTQ violence as well as prevention, recovery, and justice efforts (2) were the next most recurring subthemes in media coverage. Trends cover the rampant homophobia in the country and the frequent violence towards LGBTQ refugees. Although the media coverage on anti-LGBTQ violence in Kenya after the implementation of the mitigation measures (5) focused more on trends and cases of anti-LGBTQ violence, no correlation was reported nor implied.

\section{Domestic Violence}

The media coverage on domestic violence in Kenya before the COVID-19 pandemic (27) predominantly narrated individual cases (13). The next most recurring subthemes were the varying rates of domestic violence in Kenya (8) with a reported $40 \%$ of women experiencing domestic violence within their lifetime, and individual, governmental, nongovernmental, and corporate prevention, recovery, and justice efforts (8). The media coverage was also concerned with the consequences of domestic violence (4). Economic repercussions were identified and a report by the audit firm KPMG and telecommunications corporation Vodafone made headlines after it estimated Kenya lost Sh5 billion (roughly 39 million euros) every year as a result of working women facing domestic violence. Reported health consequences included bad mental health and physical injury. Trends of domestic violence (3) (including security force agents as perpetrators (2) and a decrease in likelihood of domestic violence with higher household incomes (1)), causes of domestic violence (3) (identified only as substance abuse (2) and jealousy (1) in this selection of articles), and legal protections from domestic violence (2) (particularly the Protection Against Domestic Violence Act (2015)) were the least covered subthemes.

Since the implementation of the COVID-19 mitigation measures, media coverage (68) has been especially concerned with the influence of the COVID-19 mitigation measures on the reported increase in domestic violence (34). This includes a $45 \%$ increase in domestic violence cases in May 2020 , and a $34 \%$ increase in calls for help related to domestic violence to a GBV hotline in the first three weeks of the dusk-todawn curfew. Causes of the increase (31) identified in the media coverage were the lockdown itself (14), the economic repercussions of the mitigation measures (14), the overall stress, fear, and uncertainty people face in times of a global health crisis (13), and increased substance abuse (4). The third most recurring subtheme in media coverage were individual cases of domestic violence (17), followed by prevention, recovery, and justice efforts (12), and legal protections from domestic violence (8).

The media also reported on the further consequences of the COVID-19 mitigation measures on domestic violence (3). These consequences included the aforementioned health issues (2) as well as a potential mental health crisis, increased Google searches 
within Kenya on finding domestic violence help (1), and extra barriers to recovery and justice services (1). The trends of domestic violence in Kenya (4) that were covered by the news media were its gradual destigmatization (1), the phenomenon of university graduate homelessness due to domestic violence (2), and a decrease in reported cases of domestic violence in June 2020 (1). The least frequently covered subthemes were similar to those covered before the implementation of the COVID-19 mitigation measures.

\section{Child Marriage}

The media coverage on child marriage in Kenya before the implementation of the mitigation measures (40) most frequently reported on prevention, recovery, and justice efforts (19). These included mostly awareness and education campaigns, rescue centers, and legal pursuits against perpetrators. The second most recurring subtheme were the consequences of this form of SGBV (14) including the discontinuation of school (12) which in turn drives cycles of poverty as well as health repercussions including psychological trauma and SRH complications (2). Individual cases of child marriage in Kenya were also frequently reported on (13), predominantly within articles that address the high prevalence of child marriage or report on prevention, recovery, and justice efforts that have provided services to these individuals. Another recurring theme were the causes of child marriage (12). They were identified as poverty (8) and retrogressive traditional beliefs including child beading (5). Legal provisions to protect from child marriage (6) as well as the national rate of child marriage (2), established at around $25 \%$ in 2019 , were the least covered subthemes by the media.
Since the onset of COVID-19 mitigation measures in Kenya, in the 41 articles concerned with child marriage, the most recurring subtheme is the causes of the increase in child marriage (23). Causes include the lockdown which closed schools and increased the vulnerability of girls to child marriage (16) and the economic repercussions of the COVID-19 mitigation measures that have disrupted livelihoods (16). There was also substantial media attention for trends of child marriage (12) such as child marriage as an important contributor to teenage pregnancy rates (11) and higher rates of child marriage in certain areas including Homa Bay, Migori, Meru, Tana River, Kwale, Siaya, Narok, and Mombasa (4). The news media reported the consequences of child marriages in times of lockdown (5) as an increase in the discontinuation of schooling (4) and lack of connection to prevention, recovery, and justice initiatives (1). News media coverage presented other subthemes similarly to its pre-pandemic coverage.

\section{Conclusion}

Our initial concern with news media as a powerful influencer of public opinion prompted inquiry into both what is known about sexual and gender-based violence in Kenya from news media coverage and how the COVID-19 pandemic has influenced this. Through the scoping review method, relevant articles were identified and charted to identify the extent, nature, and themes of SGBV coverage. The 340 included articles were analyzed with NVivo. The research team found clear trends in the digital news media coverage on SGBV in Kenya.

There was a stark increase in articles on SGBV in Kenya and increased diversity in 
news sources after the implementation of the COVID-19 mitigation measures. An increase in the share of news reports and feature articles on SGBV was also found. Thematically, FGM was the most covered form of SGBV before the pandemic. While SGBV broadly remained the most prevalent theme in news media coverage after the implementation of the mitigation measures, the share of articles reporting on domestic violence and sexual violence increased and replaced FGM as most covered form(s) of SGBV. The lockdown (including school closings and confinement to the home) and the economic repercussions of the mitigation measures were the most frequently reported causes of the increase in all forms of SGBV. The causes of SGBV were routinely reported as retrogressive cultural beliefs and poverty.

The agenda-setting role of the media has important consequences for SGBV awareness in Kenya. The increasing digitization of media outlets in Kenya and the democratization of access to internet will further contribute to broad-based sensitivity to the repercussions of SGBV on individuals and society. The media's consistent focus on SGBV, opinion pieces aligned with progressive policy, near absence of sensationalism to narrate individual cases of SGBV, and strong awareness and reporting on the causes and consequences of the COVID-19 pandemic mitigation measures shows its active role in health and development advocacy. Simultaneously, the prevalence of SGBV themes in media coverage do not accurately depict the most common types of SGBV in Kenya. FGM is less common in Kenya than domestic violence, yet digital news media coverage disproportionately reported on FGM before the pandemic. This disposition can have influence on public perception. Nonetheless, the increased and diverse coverage since the COVID-19 pandemic can further serve as a significant facilitator in raising awareness and beneficially influence public perception of necessary SGBV prevention interventions. 


\section{References}

Arksey, H., \& O'Malley, L. (2005). Scoping studies: towards a methodological framework. International Journal of Social Research Methodology, 8:1, p. 19-32, doi: 10.1080/1364557032000119616

Girls Not Brides. (2018, December 18). Kenya - Child Marriage Around the World. Girls Not Brides. Retrieved from https://www.girlsnotbrides.org/child-marriage/kenya/

McCombs, M. E. (2011). The news and public opinion: Media effects on civic life. Cambridge, UK: Polity Press.

McCombs, M. E. (2011). The Agenda-Setting Role of the Mass Media in the Shaping of Public Opinion. Retrieved from https://www.researchgate.net/publication/237394610 The Agenda-Setting_Role_of the Mass_Media_in_the_Shaping_of_Public_Opinion

Mc Evoy, C. (2012). Battering, Rape, and Lethal Violence: A Baseline of Information on Physical Threats against Women in Nairobi. Small Arms Survey. Retrieved from http://www.smallarmssurvey.org/fileadmin/docs/F-Workingpapers/SAS-WP13-VAW-Nairobi.pdf

Ministry of Health. (2020, March). Kenya Coronavirus Cases Rise to Four, CS Health. Retrieved from https://www.health.go.ke/kenyacoronavirus-cases-rise-to-four-cshealth/

Ministry of Health. (2020, April). The Government announces extra measures to prevent the spread off coronavirus Nairobi. Retrieved from https://www.health.go.ke/govt-announces-extra-measures-to-prevent-spread-of-coronavirus-nairobi-monday-april-6-2020/

Ministry of Health. (2020, July 7). President Uhuru lifts movement ban in three counties Nairobi, Monday July 6, 2020. Retrieved from https://www.health.go.ke/president-uhuru-lifts-movement-ban-inthree-counties-nairobi-mondayjuly-6-2020/

Mutahi, B. (2020, April 20). Coronavirus: The fear of being sentenced to a Kenyan quarantine centre. $B B C$. Retrieved from https://www.bbc.com/news/worldafrica-52326316

National Crime Research Center. (2014). Gender-based violence in Kenya. Retrieved from http://crimeresearch.go.ke/wp-content/uploads/2018/02/wwwroot_publications_Gender-Based-Violence-inKenya.pdf

Nyabola, N. (2020, June 25). Why Kenyans Are Protesting Police Brutality at Home and Abroad. Foreign Affairs. Retrieved from https://www.foreignaffairs.com/articles/africa/2020-06-25/why-kenyans-are-protesting-police-brutality-home-and-abroad

Reelforge \& Tifa Research. (2019, July). Kenya Media Landscape Report. Retrieved from http://www.tifaresearch.com/wpcontent/uploads/2019/07/MediaLandscape-in-Kenya-2019-ReportReelforge-and-TIFA10.07.2019.pdf

Republic of Kenya. (2015, December). Kenya Demographic and Health 
Survey 2014. Retrieved from

https://dhspro-

gram.com/pubs/pdf/FR308/FR308.

pdfNCPD-KE. (2020, November).

Nairobi

Seale, C. (2002). Media and health. London: SAGE Publications

Spectrum. (2017, January). Digital Migration Process in Kenya. Retrieved from https://www.itu.int/en/ITUR/seminars/rrs/2017-Africa/Forum/GSMA\%20Digital\%20Migration $\% 20$ Process $\% 20$ in $\% 20$ Kenya.pdf

UNFPA. (2020, April). Press Release: New UNFPA Projections predict calamitous impact on women's health as COVID-19 pandemic continues. Retrieved from https://www.unfpa.org/press/newunfpa-projections-predict-calamitous-impact-womens-health-covid19-pandemic-continues

UNHCR. (2020). Sexual and Gender Based Violence. Retrieved from https://www.unhcr.org/sexual-andgender-based-violence.html

UNICEF (2020). A Profile of Female Genital Mutilation in Kenya. UNICEF. Retrieved from https://data.unicef.org/resources/aprofile-of-female-genital-mutilation-in-kenya

UN Women. (2017). Media coverage of gender-based violence - Handbook and Training of Trainers. Retrieved from https://eca.unwomen.org/en/digital-library/publications/2017/09/media-coverageof-gender-based-violence---handbook-and-training-of-trainers

WHO. (2020, May). New WHO estimates: Up to 190000 people could die of COVID-19 in Africa if not controlled. Retrieved from https://www.afro.who.int/news/ne w-who-estimates-190-000-peoplecould-die-covid-19-africa-if-notcontrolled 